\title{
Issues Involved with Calculating the Cost of Capital in the Not-for-Profit and Public Sectors
}

\author{
Walt Schubert \\ La Salle University \\ Les Barenbaum \\ La Salle University and Financial Research Associates
}

This paper looks at issues concerned with the social rate of discount. The prime focus is on the cost of equity financing, but in the end debt financing and the net benefit flows need to enter into the net present value decision. We argue that the cost of equity to the social sector is likely to, ceteris paribus, be greater than the cost of equity to the private sector, while the cost of debt is less. The difficult area of net benefit flows when they are non-pecuniary, is noted and the philosophical issue of pre-tax and post-tax analysis is tackled.

Keywords: Cost of Capital, Public Sector, Not-for-Profit Sector

\section{INTRODUCTION}

In order to determine whether the net present value of a project is likely to be positive, the expected net cashflows (or benefit flows) are discounted at the entity's cost of capital. Our key focus will be on the equity cost of capital for the not for profit and public sectors. The cost of equity to the not-for-profit and public sectors, on top of the real return, inflation return, and the typical risk premium, also requires and extra return for a lack of liquidity, and in the public sector case perhaps a premium for being forced into the investment. We will, also, ultimately need to include the debt sector to determine the overall discount rate. Finally we will have to tackle the knotty problem of whether adjustments need to occur in the cost of capital or the net benefit part of the present value analysis.

\section{TECHNICAL ISSUES}

An entity's cost of capital is found by taking the weighted average cost of debt plus the weighted average cost of equity. Ignoring the various equity costs (i.e. retained earnings as opposed to new stock offerings, or the issuing of preferred stock), the basic formula, for a for-profit firm's cost of capital is:

$\mathrm{K}_{\mathrm{a}}=\mathrm{W}_{\mathrm{d}} \mathrm{K}_{\mathrm{d}}\left({ }^{1}-\mathrm{T}_{\mathrm{M}}\right)+\mathrm{W}_{\mathrm{e}} \mathrm{K}_{\mathrm{e}}$

Where:

$\mathrm{K}_{\mathrm{a}}=$ The entity's average cost of capital

$\mathrm{W}_{\mathrm{d}}=$ The proportion of capital raised through debt, based on the market value of the debt. 
$\mathrm{K}_{\mathrm{d}}=$ The pre-tax cost of debt

$\mathrm{T}_{\mathrm{M}}=$ The entity's marginal tax rate

$\mathrm{W}_{\mathrm{e}}=$ The proportion of capital raised through equity, based on the market value of the equity.

$\mathrm{K}_{\mathrm{e}}=$ The cost of equity

The not-for-profit and public sector formula is written as follows:

$\mathrm{K}_{\mathrm{a}}=\mathrm{W}_{\mathrm{d}} \mathrm{K}_{\mathrm{d}}+\mathrm{W}_{\mathrm{e}} \mathrm{K}_{\mathrm{e}}$.

The key concept, from the enterprise point of view, is to minimize the cost of capital. From the equation, above, it is clear that debt, for the for-profit sector, is tax advantaged and for the public sector it is not. Therefore, adding debt to equity funding should lower the average cost of capital to the for profit sector. However, due to the nature of both tax laws and residual claims, it is safe to say that non-profit and public sector debt is likely to be lower than is their cost of equity. At the state level, treasury security interest, the interest on local municipal bonds, and the interest on non-profit-bonds is generally not taxable and at the federal level, investors do not pay federal income tax on the interest earned on investments in not-for-profit and municipal bond investments. Corporate bond interest, however, is typically taxable at the federal, state, and possibly local levels. Therefore, whether the net cost of debt is greater for for-profit firms or similarly risky not-for-profit entities and municipalities rests on the difference between investor (personal) and corporate tax rates. Currently, the highest marginal tax rate for individuals is 37 percent and the highest corporate rate is 21 percent. $^{1,2}$ Therefore it is quite likely that the cost of debt of two otherwise similar bonds would be cheaper to finance for the not-for-profit and municipal bond sector than the for profit sector.

Further while the advantage of taxes to debt financing is clear, at some level of debt, creditors worry about the entity generating enough cashflow to meet its debt service obligations, and equity holders begin to be concerned about their payoff since they are the residual claimants. As a result, at some level of debt to equity, the average cost of capital begins to rise.

The cost of debt and the cost of equity share the need to earn a real rate of return on an investment and, therefore, must include inflation protection. Where they differ is in the payment to risk. Equity is more risky than is debt since equity holders are residual claimants to the entity's performance. Debtholders typically do not share in the victories or defeats of the entity. Bondholders receive the agreed upon return and what is left over belongs to equity holders. There is no legal obligation to pay equity holders a return.

The required rate of return on a debt instrument, after taxes, is based on the same qualitative assumptions in all three issuer cases. That is, the required rate of return after tax is a function of the real rate of return, the expected inflation rate, and a risk premium.

In recent years, attention has been paid to the reality that some investments have flexibility, so that if the actual returns exceed expectations, investment augmentation can take place thereby increasing returns above those originally expected, and if actual returns are disappointing, strategies to decrease the loss may be available. The flexibility is known as a real option. The availability of real options makes an investment more valuable. In what follows, however, we will stick to the traditional view of the cost of capital.

\section{THE COST OF EQUITY IN THE FOR-PROFIT SECTOR}

It is generally perceived that the equity investment in for-profit entities is typically an issue of risk and return. Risk is a constraint and return is the goal. In addition to the need to capture a real return for abstinence, a real return for taking on liquidity risk and the risk of poor performance also needs to be earned. When a private sector investor expands their utility function to include social values or aesthetic wants the risk function becomes more sophisticated. In the former case, diversification benefits are reduced and in the second case liquidity issues gain in prominence. Typically then, adjustments need to be made both to the risk premium and to the expected cashflows. We will here, however, stick to the notion that the vast majority of private sector investment is of the generic two parameter utility function type. 
Our focus is on the cost of equity capital for the not-for-profit and public sectors. When speaking of the required rate of return on equity, analysts typically focus on the same set of variables as they do for bonds. That is the required rate of return on an equity investment is a function of the real rate of return, inflation protection, a risk premium, and taxes. In the end, we are comparing investments. That fact leads us to the conclusion that the issue of investment choice breaks down to opportunity cost. What is the best thing I can do with my money? This argument is known as the opportunity cost approach or in the case of the non-profit or government sectors the Social Opportunity Cost of Capital. ${ }^{3}$ It is the approach that we will employ here.

Our question is, is the investment in not-for-profit or government enterprises fundamentally different from investing in the private sector, and does that show up in the cost of equity? Our answer is that there are fundamental differences in both the riskiness of the investments and the nature of the net benefit flows between investing in the not-for-profit and government sectors compared to the private sector and that those differences will impact the cost of equity.

\section{THE COST OF EQUITY CAPITAL FOR THE NOT-FOR PROFIT SECTOR}

Employing equity capital to the not-for-profit sector is akin to the general investment-consumption decision. Most investments in not-for-profit organizations are designed to return a non-pecuniary benefit. The investor is typically not looking for a cash return on their investment and does not expect to get their money back. There is, in short, no liquidity risk. That, however, is because there is no liquidity. The money is gone. Does the lack of liquidity add to the equity cost of capital? The answer is yes.

Purchasing power and disappointing performance risk continues to matter in the sense that dollar investments will typically bring in less non-pecuniary benefits when inflation is greater than the predicted level. It can be argued that unexpected inflation costs are captured in the actual net benefit component of the net present value ex post outcome. However, that is true with for profit investments as well. There is, of course, still risk of poor performance. Disappointment with the outcome generated by the investment in a non-profit is a real possibility.

Other issues to consider in non-profit investing include the difference in temporalness compared to other equity investments. Non-profit investors may be willing to delay gratification for longer periods than investors in for profit companies and government. Investments in healthcare and education in developing countries, for example, have long shelf lives and require donors willing to understand the slow progress of development. Does that show up in a lower risk premium? Perhaps. This is not to imply that investors do not expect results. In fact, modern investors in not-for-profit enterprises seem keener to see measurable results than in the past.

There is also a type of management risk, of which it is difficult to get a clear picture. Not-for-profit managers can be passionate and possibly even more efficient than their for profit counterparts, but without an eye on net cashflow, results may be more difficult to measure, and management proficiency more difficult, though not impossible, to assess. That is, clear-cut goals and performance measurements may be more difficult to identify and assess in the not-for-profit sector.

While certain differences between investments in for profit vis-à-vis not for profit enterprises may be differences of degree rather than kind, the lack of liquidity and the importance of non-pecuniary benefits are special features of investing in a not-for-profit venture.

When the benefit flows are non-pecuniary, how should return and risk be measured? If an investor in a not-for-profit invests in order to inoculate children against a communicable disease, it is possible to count the number of children who receive the inoculation. However, what does the probability distribution around the expected inoculation number actually tell us about risk and can that be foretold with any kind of accuracy? Typically, finance treats risk as a statistical concept. Finance professionals value the probability of various outcomes. The greater the standard deviation of those outcomes, the greater the risk. In fairness, while mathematicians and economist may argue that without a known probability distribution risk cannot be calculated, professional financial managers often act as if they have some idea of what risk looks like even though the distribution is unknown. Whether or not we should 
build the hospital in Botswana is a crucial experiment. I only get to do it one time. In general not-forprofits and public sector entities face a portfolio of crucial experiments.

Measuring the return is also difficult. What if the investment is designed to create a better lifestyle for shut-ins? Is the benefit really to be measured by the number of shut-ins serviced or does the quality of the service matter? The same may be said about non-profits who try to build schools, provide desks, or provide teachers and books, or religious services. Do numbers translate well to outcomes and how should outcomes be measured? At this point in time, it seems that the only proof that non-pecuniary benefits outweigh the cost, in present value terms, is if the investor continues to consistently provide more funding to the non-profit organization.

\section{FOR PROFIT VS NOT-FOR-PROFIT SECTOR COST OF EQUITY}

There is a strong argument that the basic cost of equity capital should be valued in the same manner for both for-profit and not-for-profit investments. The equity capital is voluntarily invested. A key issue, however, is that the not-for-profit investment will generally have lower liquidity and therefore, require a greater liquidity premium. While it may be empirically true that it is more difficult to measure not-forprofit returns and that investors are willing to take on more risk in order to "do good", than they would to earn a higher pecuniary return, the basic model for delineating the required rate of return on investment is the same.

There is also a question about the nature of the net benefit flows. There is a notion that investments in not-for-profit organizations are seen as creating what we might think of as super-charged benefits. Investors invest in non-pecuniary activities because they tend to see them as particularly socially, psychologically, or even politically important. That argument seems to find its way not into the cost of capital but rather into the valuation of the net benefit. Sustained investments in non-pecuniary activities would tend to indicate investor satisfaction with the outcomes. That is, the net present value of investment activities is positive, even though, due to liquidity issues, the cost of equity is greater than for private sector investing. In sum, it is improper to focus on the cost of capital without considering the net benefit analysis as well.

\section{THE COST OF EQUITY TO THE PUBLIC SECTOR}

We argue that the best approach in analyzing difference in the cost of capital between different sectors is the opportunity cost approach. When it comes to the public sector, not all analysts agree. An alternative approach is known as the Social Rate of Time Preference and it seeks to find the time value of alternative consumption paths. ${ }^{4}$ This model is based on the notion that public projects do not have ready alternatives and that the decision-maker, not the equity holder, makes the investment decisions. It is our view that this phenomenon is better captured in the liquidity risk part of the opportunity cost approach and possibly through a return to duress.

The equity investment in the public sector is not voluntary. Equity in the public sector is called taxes and taxes are paid by fiat. However, the equity cost of capital to the government still needs to be calculated. In practice, governments run the gamut between not only employing the social opportunity cost or social rate of time preference models but also some public entities default to a simple discount rate rule. $^{5}$ A study by Mark Harrison for the Australian Productivity Commission from 2010 does argue for the Social Opportunity Cost approach. ${ }^{6}$

While most citizens, presumably, would be willing to pay some taxes, and some citizens may be willing to pay more taxes than they actually are required to pay, a problem is both the forcing of the equity investment and the severing of the income consumption link. When an investor makes and equity

investment in a for profit or not-for-profit company they do so with a relatively clear idea of what they would like in return. They also make the investment voluntarily. Public sector investing is different. Practically speaking, the government has the legal right to force an equity investment. However, also practically speaking, in a republic, if voters, on aggregate, find the investment/return trade-off 
unsatisfying they can change the decision-makers. Even non-democratic societies face some pressure to assure stability by employing tax funds to ends that create some level of benefit (return) to their equity investors. Therefore, the employment of public sector equity financing must be done with care.

Like not-for-profit equity investors, public sector equity investors lack liquidity since their contributions cannot generally be liquidated. In addition, like, not-for-profit, and for profit equity investors they do face expected and unexpected inflation risk and the risk that outcomes will be disappointing. Therefore, like not-for-profit investors, public sector investors face a similar set of variables and might have the same required rate of return. Their return requirements differ from the forprofit sector due to a lack of liquidity. However, the public sector equity investor also differs from both the for-profit and not-for-profit investor in the sense that the equity investment is not voluntary.

In the for-profit and not-for-profit sector investors willingly make their investment and in the public sector equity investing is determined by fiat and compliance. How should we think about the difference? Should we assume that the required rate of return would be higher on a forced investment? Surely, being forced to finance government is at least part of the reason why citizens are often unhappy with government performance. While finance argues that economic agents should think in terms of after tax outcomes, it is clear that most citizens see their wage income as pre-tax. We can argue that the involuntary nature of the equity investment in the public sector requires a further return. We can call that return a return to duress. It is likely then, that the equity investor in the government sector requires a greater return than does their not-for-profit counterpart in the form of a return to duress.

A further complication comes in the form of the net benefit flows. Investors in the for-profit and notfor-profit sectors are likely to have relatively the same desired outcomes as their fellow equity investors. Alternatively, public sector investors may not have the same benefits in mind. Further, even if the candidate(s) we voted for win(s), it is still unlikely that we would agree with all their policy prescriptions. As an equity investor in the public sector, that is a taxpayer, an investor receives a portfolio of policies. An investor's interaction with that portfolio can be widely different from that of another taxpayer. If I am fearful of immigrants or believe the country is "full", I may believe a border wall is a great investment. However, if I believe in the free flow of labor or worry about the dangers that immigrants face at home, I may feel an investment in a wall is a social atrocity and a waste of taxpayer money. In short, while one investor in a for-profit or not-for profit enterprise may disagree with another investor about how well the entity in which they invested performed, it is likely that the disagreement is one of degree. However, the investment in the portfolio of government activities may lead to huge discrepancies in how investors valued government performance. Therefore, an investor's assessment of the return on the equity investment is going to depend on both their personal interactions with government policy and their personal view of the trade-off between personal gain and societal wants. The net benefit flows are found in the numerator but should be invariant to the individual's assessment of their required rate of return on their equity investment. Alternatively, the actual outcome will speak to whether or not the required rate of return was reached!

\section{SUMMARY SO FAR}

By now, it is probably clear, that the argument in this paper is that unlike the For-profit-sector where equity liquidity premiums are generally a matter of degree, the not-for-profit sector and the government sector both require a premium for the lack of any liquidity. In addition, we argue that, ceteris paribus, forcing equity investment in the public sector requires yet another premium for the required rate of return on duress.

In sum, we argue that the cost of equity capital to an average investor should be greatest in the public sector, second highest in the not-for profit sector, and lowest in the private sector. What this implies, is that for an average investor, the public sector would need to grow the greatest net benefit flows to end up with the same net present value as the not-for-profit and for profit sectors. Similarly, the not-for-profit sector should require a greater rate of return than does the private sector.

Journal of Applied Business and Economics Vol. 21(5) 2019105 
The arguments launched above, however, are based on the required return to equity. The required return overall also includes the required return on debt. In this case, we often see that the required return on debt instruments is lower in the public and non-profit sector. In many cases, this is due to tax laws favoring the debt issues of the public and non-profit sector, but also, particularly in the United States Treasury market, lower default risk premiums and lower liquidity risk premiums cause the cost of the federal government debt to be lower.

In the final analysis, the cost of capital is calculated by employing the formulas noted earlier in the paper. Given that risk is the same, we would argue that the public sector would have the greatest equity cost of capital due to premiums for a lack of liquidity and a premium for forced equity investment. The not-profit sector would also have a greater cost of equity capital than the for profit sector due to a lack of liquidity. The overall cost of equity capital however, could be greater for private sector investments if it was deemed that the net benefit flows were likely to be more variable than either the public sector or notfor profit sectors.

\section{OTHER ISSUES}

\section{The Net Benefits in the Net Present Value Equation}

The numerator in the present value calculus is, of course, as important as the denominator. When we speak of the private sector, the numerator is generally a net cashflow concept. As we noted above, private sector investors may care about social or aesthetic benefits, but generally, we are arguing that the net benefits are about net cashflow discounted to the present time.

We have already mentioned the possibility that investors in not-for-profit enterprises see the benefits of those investments to be super-charged. This is certainly the case when investors continuously add equity capital to the same not-for-profit entity. Although behaviorists quite rightly note the limitations of rational economic choice, we still argue that rational economic units prefer to maximize their financial utility. That is, they attempt to allocate their capital to the ends that maximize their expected welfare.

The voluntary nature of the equity investment in non-for-profits implies that they may earn a "supercharged" benefit to their investors. Since often, the not-for-profit benefit is non-pecuniary, investors (that is donors) must believe those benefits net of costs and discounted to the present exceed the benefits of a similar or even less risky investment in the for-profit sector. It is, in short, crucial to understand the net benefit flows in order to assess the efficacy of not-for profit investments.

\section{Tyranny?}

Our work above also opens up the door to argue for the "tyranny" of the government sector. Equity investors are forced to invest in government enterprise. However, it would be wrong to assume that everyone is unhappy with his or her equity investment. Most, though probably not all, citizens recognize the need for public spending running anywhere from transportation systems to public education to defense operations. These enterprises all require investment. Due to the break-up of the income consumption link and the forced taxation that takes place, there are probably few, if any, investors, who think that everything in which the government invests is a good idea. Yet probably the vast majority of taxpayers recognize a benefit to government investment.

Unlike most for profit investments in which the goal is money, or not-for-profit investments in which most equity investors have the same goal, equity investors in government have widely different interpretations of the net benefits earned from a public investment. It still holds true, however, that all public sector investments should be undertaken only if the "corporate" view is that the net present value of the investment is positive. Too many mistakes will lead, in a republic and possibly in a dictatorship as well, to a change in government leadership.

\section{What About the Hive?}

On a philosophical plane, there may be a problem with arguing that employees and financiers work only for themselves and their firm but not for the general good. In finance, we constantly remind students 
and investment clients that the key goal is real after tax return, not nominal return. Worker compensation and investor returns are limited by other costs to the enterprise. We do not typically consider the fact that the firm has additional expenses beyond wages and benefits and the return to investors as tyranny against either group. The public sector also has expenses that need to be financed. Can it be argued then that workers and financiers, irrespective of whether they are employed or invested in for profit, not for profit, or the public sector, work for both the firm and the common good? In that case, it is reasonable to argue that there is no tyranny and therefore there should be no tyranny premium.

If for profit or not for profit entities fail to properly convey benefits to workers or their financiers both groups have the option to leave that job or investment. While the transaction expense of leaving the reach of the tax district is high, at least in republics, if the general view is that the common good is not well served, the government in power can be voted out of office. In sum, we can take the view that both workers and capitalists are obliged to work for, or finance, both their for profit and not for profit ventures directly, but are also obliged to finance indirectly the public sector for the common good. That is, it can be argued that the government is not taxing "your" money, but rather that taxes are part of the cost of running the economy. "My" money then, as argued in financial theory, is actually the after tax component. That is, both the operations of the enterprise for whom we work or for whom we are invested and the common good needs to be financed before we are left with our personal share of the economy. We work for the real after tax compensation whether it is labor, debt, or equity.

\section{SUMMARY}

Under traditional analysis, we show that the government's equity cost of capital is likely to be the greatest of the three economic sectors (government, not-for-profit and for profit), followed by the not-for profit sector and lastly the for-profit sector. Debt costs are likely to be exactly the opposite implying that the government sector should be the most leveraged followed by the not-for-profit sector and finally the for profit sector. Individual for-profit, not-for-profit, and government units' cost of capital will, of course, vary due in large part to their financial health.

Further, if we argue that taxes are simply an indirect cost of running a well-functioning economy, we can reasonably assess taxes as a cost similarly to operating costs for for-profit firms under which various inputs must be paid including labor and material costs. Taxes represent payment for the common good similar to any business costs. If it is philosophically true that we are required to work for the good of the firm and the common good, then the return to work and finance is the after tax return and no premium for tyranny should be included in the cost of equity capital for the public sector.

\section{ENDNOTES}

1. Taxfoundation.org/2019-tax-brackets/.

2. Tradingeconomics.com/corporate-tax-rate.

3. Creedy, J. and Passi, Hemant, Public Sector Discount Rates: a Comparison of Alternative Approaches, The Australian Economic Review, Vol 51, p. 143. 2018.

4. Ibid. Creedy, J. and Passi, Hemant.

5. Spackman, Michael, Social Time Discounting: Institutional and Analytical Perspectives, Centre for Climate Change Economics and Policy, Working Paper No. 207, March, 2015.

6. Harrison, Mark, Valuing the Future: the Social Discount Rate in Cost-Benefit Analysis. Australian Government Productivity Commission. April 2010. 


\section{REFERENCES}

Creedy, J., \& Passi, H. (2018). Public Sector Discount Rates: a Comparison of Alternative Approaches, The Australian Economic Review, 51, 143. 2018.

Harrison, M. (2010, April). Valuing the Future: The Social Discount Rate in Cost-Benefit Analysis. Australian Government Productivity Commission.

Spackman, M. (2015, March). Social Time Discounting: Institutional and Analytical Perspectives. Centre for Climate Change Economics and Policy. Working Paper No. 207.

Taxfoundation.org/2019-tax-brackets/. (2019).

Tradingeconomics.com/corporate-tax-rate. (2019).

108 Journal of Applied Business and Economics Vol. 21(5) 2019 